\title{
Bismuth chelate as a contrast agent for X-ray computed tomography
}

 \\ Ming-yue Chen ${ }^{1}$, Jie-xia Li', Yu Zhang ${ }^{1}$, Jing-ping Liư ${ }^{3}$, Yuan-ye Dang ${ }^{1}$, Dan Wu' ${ }^{1}$ Xiao-ya Zhao', \\ Zhong-xiao Lin', Yin-lei Lin', Song-pei Li ${ }^{* *}$ and Ling-yan Zhang ${ }^{2^{*}}$
}

\begin{abstract}
Backgrounds: Due to the unexpected side effects of the iodinated contrast agents, novel contrast agents for X-ray computed tomography (CT) imaging are urgently needed. Nanoparticles made by heavy metal elements are often employed, such as gold and bismuth. These nanoparticles have the advantages of long in vivo circulation time and tumor targeted ability. However, due to the long residence time in vivo, these nanoparticles may bring unexpected toxicity and, the preparation methods of these nanoparticles are complicated and time-consuming.

Methods: In this investigation, a small molecular bismuth chelate using diethylenetriaminepentaacetic acid (DPTA) as the chelating agent was proposed to be an ideal CT contrast agent.

Results: The preparation method is easy and cost—effective. Moreover, the bismuth agent show better CT imaging for kidney than iohexol in the aspect of improved CT values. Up to $500 \mu \mathrm{M}$, the bismuth agent show negligible toxicity to L02 cells and negligible hemolysis. And, the bismuth agent did not induce detectable morphology changes to the main organs of the mice after intravenously repeated administration at a high dose of $250 \mathrm{mg} / \mathrm{kg}$. The pharmacokinetics of the bismuth agent follows the first-order elimination kinetics and, it has a short half-life time of $0.602 \mathrm{~h}$. The rapid clearance from the body promised its excellent biocompatibility.
\end{abstract}

Conclusions: This bismuth agent may serve as a potential candidate for developing novel contrast agent for CT imaging in clinical applications.

Keywords: Bismuth agent, DTPA, X-ray computed tomography, lohexol

\section{Background}

X-ray computed tomography $(\mathrm{CT})$ produces crosssectional images of internal organs and structure of the body. Contrast agents (CAs) enhance the visibility of specific regions such as tissue, organs and blood vessels during CT scan. There are two types of CAs currently

\footnotetext{
*Correspondence: fujj@gzhmu.edu.cn; lisongpei@foxmail.com; sdzly@smu.edu.cn

${ }^{\dagger} \mathrm{Ji-jun}$ Fu, Jun-jie Guo and Ai-ping Qin contribute equally to this work ${ }^{1}$ The Fifth Affiliated Hospital of Guangzhou Medical University, Guangzhou Medical University, Guangzhou 510700, Guangdong, China 2 Department of Medical Imaging, The Third Affiliated Hospital, Southern Medical University, Guangzhou, China

Full list of author information is available at the end of the article
}

available for clinical use, small molecules including iodinated contrasts agents (ICAs) as well as newly'developed nanoparticles. These agents are typically administrated intravenously for well-perfused organs or orally for imaging of gastrointestinal organs. In both cases, in addition to emphasize a high performance on imaging, special attention should be paid to the safety of CAs. It is well recognized that lower the dosage of administration is favorable to suppress the toxicity of CAs. Therefore, nanoparticles such as lanthanide nanoparticles [1] and gold nanoparticles [2] are emerging as potential CAs for CT, which can be used at lower dose than traditional CAs and optimized for targeting. However, the high cost and complexity of manufacture have hampered the clinical

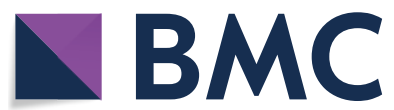

(c) The Author(s) 2020. This article is licensed under a Creative Commons Attribution 4.0 International License, which permits use, sharing, adaptation, distribution and reproduction in any medium or format, as long as you give appropriate credit to the original author(s) and the source, provide a link to the Creative Commons licence, and indicate if changes were made. The images or other third party material in this article are included in the article's Creative Commons licence, unless indicated otherwise in a credit line to the material. If material is not included in the article's Creative Commons licence and your intended use is not permitted by statutory regulation or exceeds the permitted use, you will need to obtain permission directly from the copyright holder. To view a copy of this licence, visit http://creativeco mmons.org/licenses/by/4.0/. The Creative Commons Public Domain Dedication waiver (http://creativecommons.org/publicdomain/ zero/1.0/) applies to the data made available in this article, unless otherwise stated in a credit line to the data. 
application of these nanoparticles. Until now, ICAs are still the most frequently used CAs for CT imaging.

There are four types of ICAs for clinical application, ionic monomeric, ionic dimeric, nonionic monomeric and nonionic dimeric [3]. All of them are derivatives of tri-iodobenzoic acid. The overall incidence of side effects induced by ICAs have been suggested to be over $1 \%$ [3, 4], including life-threatening adverse event [5]. The side effects induced by ICAs are partially attributed to their hypertonic or hypotonic properties. Although the third generation ICAs, namely nonionic dimer such as iodixanol, possesses iso-osmolality and are believed to induce lower incidence of side effects [6], they still may lead to nephropathy and adverse cardiac events [7-10].

Bismuth preparations are widely used in quadruple therapy for Helicobacter pylori (H. pylori) and the treatment for gastrointestinal disorders such as gastric and duodenal ulcer. A meta-analysis including 35 randomized controlled trails have suggested that no serious side effects were induced by bismuth therapy [11]. In addition, bismuth is one of the most widely used element in nanoparticle contrast agents [12]. Nanoparticles are emerging vesicles for contrast agents with the advantage of long residence time and targeting capacity [12]. However, a cost-effective approach is needed to synthesize nanoparticles in a large scale and its safety needs to be assessed by large scale clinical trials.

In the present study, we constructed a bismuth and diethylenetriaminepentaacetic acid (DTPA) complex and evaluated its potential as CAs for X-ray CT. DTPA has been widely used in lanthanide-based magnetic resonance imaging (MRI) contrast medium, such as Magnevist for the imaging of blood vessels, brain and spin as well as Primovist, a liver-specific CAs. The toxicity and imaging capacity of this bismuth agent was tested in both in vitro and in vivo models. The pharmacokinetics of the bismuth agent was measured in mouse and analyzed by DAS 2.0 software. This study may provide a potential candidate for novel CAs with low toxicity and can be synthesized by cost-effective approaches.

\section{Methods}

\section{Materials}

$\mathrm{Bi}_{2} \mathrm{O}_{3}, \mathrm{Bi}\left(\mathrm{NO}_{3}\right)_{3}$, DTPA and $\mathrm{NaOH}$ were purchased from Aladdin Company (Shanghai, China). The live-dead assay kit and methyl thiazoly tetrazolium (MTT) were purchased from Beyotime Biotechnology (Shanghai, China). Dulbecco's modified Eagle's medium (DMEM) was bought from Gibco Corporation.

\section{Synthesis of the bismuth agent}

The bismuth agent was simply prepared by heating $\mathrm{Bi}_{2} \mathrm{O}_{3}$ and DTPA in deionized water. In details, $\mathrm{Bi}_{2} \mathrm{O}_{3}$
$(0.5 \mathrm{mmol})$ and DTPA $(1.0 \mathrm{mmol})$ were added to $10 \mathrm{~mL}$ of deionized water, the cloudy mixture was stirred at $80{ }^{\circ} \mathrm{C}$. After about $1 \mathrm{~h}$, the mixture turned from cloudy yellow to clear transparent solution, indicating the end of the reaction. After cooling to room temperature, the solution was filtered through $0.8 \mu \mathrm{m}$ filter to remove the un-reacted $\mathrm{Bi}_{2} \mathrm{O}_{3}$ or DTPA. The concentration of the bismuth agent was measured by atomic absorption spectrum. Before treating animals, the $\mathrm{pH}$ value of the solution should be adjusted to 7.0 by adding $\mathrm{NaOH}$.

\section{Characterization of the bismuth agent}

The bismuth agent without adding $\mathrm{NaOH}$ was freezedried and used for the following characterizations. The formation of the chelate was confirmed by ultravioletvisible (UV) spectrum, the Fourier transform infrared spectrum (FTIR), nuclear magnetic resonance spectroscopy ( $\left.{ }^{1} \mathrm{H}-\mathrm{NMR}\right), \quad \mathrm{X}$-ray photoelectron spectroscopy (XPS) and mass spectrum (MS). The bismuth agent and DTPA was dissolved in deionized water and diluted to the concentration of $75 \mu \mathrm{g} / \mathrm{mL}$, the UV spectrum of both solutions was compared. The bismuth agent and DTPA was dissolved in $\mathrm{D}_{2} \mathrm{O}$ to a final concentration of about $10 \mathrm{mg} / \mathrm{mL}$ and, the ${ }^{1} \mathrm{H}$-NMR was measured. To validate the molecular weight of the bismuth agent, ionization mass spectrum (ESI-MS) of the chelate was analyzed.

\section{The stability of the bismuth agent}

After adjusting the $\mathrm{pH}$ value of the bismuth agent to 7.0, the solution was stored at $4{ }^{\circ} \mathrm{C}$ for 4 months. Before and after the storage, the Nano-Particle Sizing System (Malvern) and transmission electron microscope (TEM) were used to detect any insoluble particles to assess its physical stability. In addition, after the storage, the solution was freeze-dried to get the powder and analyzed by IR spectrum to determine its chemical stability.

\section{Biocompatibility of the bismuth agent in vitro}

The human liver cell line L02 was used to evaluate the in vitro biocompatibility of the bismuth agent. DMEM was used as the media.

Twenty thousand of L02 cells were seeded in 24-well plate and incubated overnight to allow cell adhesion. Then, the bismuth agent was added to the cells to make a final concentration of $500 \mu \mathrm{M}$. The cells were allowed to grow for another $24 \mathrm{~h}$ before carrying out the live-dead assay according to the kit protocol. Calcein-AM is able to label the living cells and, propidium iodide (PI) stains the nucleus of the dead cells. MTT experiment was also used to measure the viability of the L02 cells. In details, five thousand cells seeded in 96-well plate and incubated overnight to allow cell adhesion. Then, the bismuth agent was added to the cells to make a serial concentrations of 
$0,2.5,6.0,12.5,25,50,125,250,500 \mu \mathrm{M}$. After incubation for another $24 \mathrm{~h}$, the viability of the cells was analyzed by MTT method.

\section{In vitro and in vivo $\mathrm{CT}$ imaging of the bismuth agent}

The bismuth solutions of a serial concentrations of 0,1 , $2,5,10,20,50 \mathrm{mM}$ were prepared, their $\mathrm{CT}$ values were measured by CT instrument (Philips, $120 \mathrm{kV}, 100 \mathrm{~mA}$ ). The commercially available iohexol was used as a control. The CT values of the diluted iohexol solutions with the same concentrations of iodine element were also measured and compared to those of the bismuth agent.

In this study, KM mice were used in all the animal experiments. The mice were given free access to food and water throughout the experiment. The animal experiments were approved by the ethic committee of Guangzhou Medical University.

The bismuth agent or iohexol was intravenously administered to the mice at the dose of $250 \mathrm{mg} / \mathrm{kg}$. The CT images were obtained immediately after the administration and at the time points of 45, 90, 120 min (Aloka, Japan, $80 \mathrm{kV}, 40 \mu \mathrm{A}$ ). The CT values of the organs at different time points were measured and, 3D images were also constructed.

\section{In vivo distribution and pharmacokinetics of the bismuth agent}

To analyze the in vivo distribution of the bismuth agent, the chelate was intravenously administered to the mice at the dose of $250 \mathrm{mg} / \mathrm{kg}$. Two hours after the administration, the mice were sacrificed and the main organs of heart, liver, spleen, lung and kidney were dissolved in concentrated nitric acid at $70{ }^{\circ} \mathrm{C}$ for $2 \mathrm{~h}$. Then, the samples were diluted by deionized water and, the bismuth element concentration was quantified by atomic absorption spectrum (AAS).

To investigate the pharmacokinetics of the bismuth agent, the chelate was intravenously administered to the mice at the dose of $250 \mathrm{mg} / \mathrm{kg}$. Before the administration and $15,40,50,60,70,80,90,100,110,120,130,150 \mathrm{~min}$ after the administration, $10 \mu \mathrm{L}$ of the blood was collected from the tail and dissolved in concentrated nitric acid. Then, the samples were diluted by deionized water and, the bismuth element concentration was quantified by AAS. The blood concentrations were analyzed by DAS 2.0 software to study the pharmacokinetic parameters of the bismuth agent, including the elimination rate constant $(\mathrm{k})$, initial plasma concentration $\left(\mathrm{C}_{0}\right)$, the halflife time $\left(t_{1 / 2}\right)$, the apparent distribution volume $(\mathrm{V})$, the clearance $(\mathrm{CL})$ and the area under the curve $\left(\mathrm{AUC}_{0 \rightarrow \infty}\right)$.

The standard samples of the bismuth element were prepared by dissolving $\mathrm{Bi}\left(\mathrm{NO}_{3}\right)_{3}$ in $10 \%$ nitric acid solution and diluted by deionized water to get a serial concentrations of $0,0.5,1,2,5,10,20 \mathrm{ppm}$.

\section{Hemolytic test and the in vivo biocompatibility}

Mouse blood was collected and centrifugated at $800 \mathrm{rpm}$ to get the red blood cells (RBCs). Then, the RBCs were washed by saline twice. Then, $900 \mu \mathrm{L}$ of the bismuth agent solutions with saline as the solvent (after $\mathrm{pH}$ adjustment) was added to $100 \mu \mathrm{L}$ of the RBC sample to get a serial concentrations of $10,20,50,100,200,500,1000 \mu \mathrm{M}$. The RBCs treated by deionized water or saline was used as the positive or negative control, respectively. The samples were left undisturbed for $24 \mathrm{~h}$, and then, were centrifugated to discard the cells and, the visible absorption at $540 \mathrm{~nm}$ of the supernatant fluid was measured.

To evaluate the in vivo biocompatibility of the bismuth agent, the mice were intravenously treated by the chelate at $250 \mathrm{mg} / \mathrm{kg}$ at day $0,2,4,6$. At day 7 , the mice were sacrificed and the main organs of heart, liver, spleen, lung and kidney were sliced and $\mathrm{H} \& \mathrm{E}$ stained. Morphology of the main organs were pictured and analyzed to evaluate the systemic toxicity of the chelate.

\section{Statistic analysis}

All values were expressed as mean \pm standard deviation (SD). All comparisons were performed by the two-tailed Student's $t$ test. A $p$ value less than 0.05 was taken as statistically significant.

\section{Results}

Preparation and identification of bismuth-based contrast agent

The bismuth agent was prepared simply by heating $\mathrm{Bi}_{2} \mathrm{O}_{3}$ with DTPA at $85{ }^{\circ} \mathrm{C}$ in deionized water. The formation of the chelate was identified by FTIR, UV and ${ }^{1} \mathrm{H}$ NMR spectrum. In Fig. 1a, DTPA alone showed vibration bands at 1730, 1700 and $1630 \mathrm{~cm}^{-1}$, indicating the presence of $\mathrm{C}=\mathrm{O}$ in carboxyl group. After the chelation with bismuth, a single peak at $1600 \mathrm{~cm}^{-1}$ was observed, indicating the $\mathrm{O}-\mathrm{C}-\mathrm{O}$ stretch. The results confirmed the coordination between carboxyl group and $\mathrm{Bi}^{3+}$. As shown in the UV spectrum (Fig. 1b), DTPA had a single peak absorption at approximately $200 \mathrm{~nm}$. The bismuth agent showed an additional absorption peak at approximately $278 \mathrm{~nm}$. The formation of the chelate was further identified by ${ }^{1} \mathrm{H}$ NMR spectrum (Fig. 1c). After the chelation with bismuth, a singlet and multiplet representing $\mathrm{CH}_{2}$ were replaced by complicated multiplets in ${ }^{1} \mathrm{H}$ NMR spectrum, suggesting the formation of chelate with bismuth. The XPS spectrum in Fig. 1d further indicated the successful chelation of Bi element with DTPA. In the mass spectra (Additional file 1. Fig. S1), the $\mathrm{m} / \mathrm{z}$ peak at 600.1000 stands for $[\mathrm{M}+\mathrm{H}]$ of the compound and, 

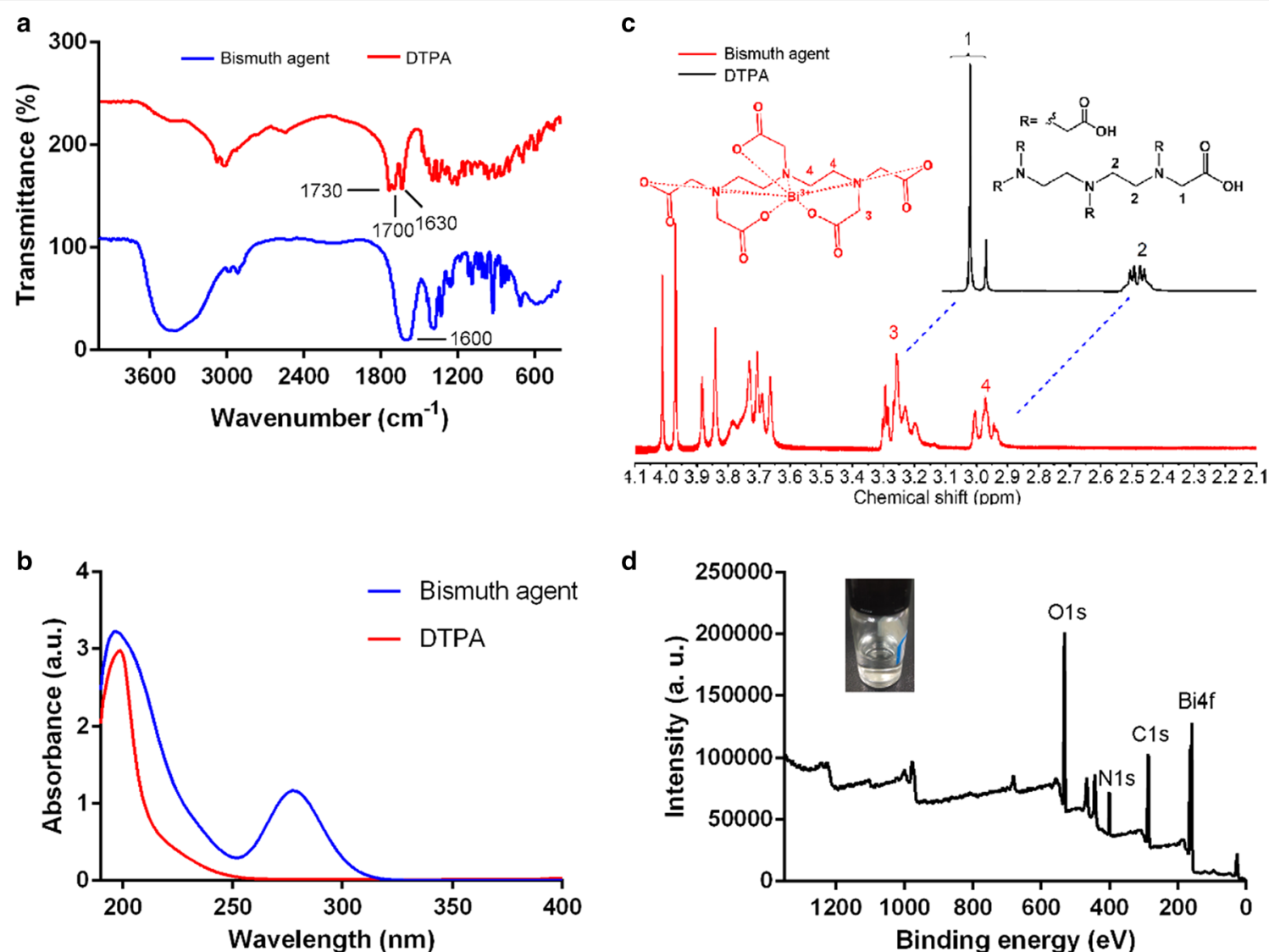

Fig. 1 The (a) FTIR spectrum, (b) UV spectrum and (c) ${ }^{1} \mathrm{H}-\mathrm{NMR}$ spectrum of the bismuth agent and DTPA, (d) XPS spectrum of the bismuth agent (insert: the picture of bismuth agent in solution ( $\mathrm{pH} 7.0$ ) after storage at $4^{\circ} \mathrm{C}$ for 4 months)

matches well with the theoretical molecular weight of the bismuth agent.

After storage of the bismuth agent (pH7.0) at $4{ }^{\circ} \mathrm{C}$ for 4 months, the solution was transparent (Fig. 1d insert) and, insoluble particles were not detectable by TEM and dynamic light scattering (DLS) method. The result implied the good physical stability of the bismuth agent. The bismuth agent (pH7.0) after storage displayed similar IR spectrum (Additional file 1. Fig. S2) to the newly prepared agent (Fig. 1a), with the typical single peak at $1600 \mathrm{~cm}^{-1}$. The result indicated the excellent chemical stability of the bismuth agent.

\section{Toxicity and performance on CT imaging in vitro}

The toxicity of synthesized bismuth agent was firstly evaluated by using calcein-AM and PI to stain live and dead cells, respectively. As shown in Fig. 2a, there is no indication of increased number of dead cells when bismuth agent was added to L02 cells at the concentration of $500 \mu \mathrm{M}$ for $24 \mathrm{~h}$, the cell morphology and viability was similar to the control group. The toxicity was further assessed by MTT method (Fig. 2b). The results showed that bismuth agent did not induce apparent reduction in cell viability up to the concentration of $500 \mu \mathrm{M}$. Both results confirmed excellent biocompatibility of the bismuth agent.

The performance of bismuth agent on CT imaging were evaluated in vitro. As shown in Fig. 2c, compared with iohexol, bismuth chelation showed significantly enhanced brightness on imaging at the serial concentrations of $1,2,5,10$, and $20 \mathrm{mM}$. Figure $2 \mathrm{~d}$ showed a linear regression between $\mathrm{CT}$ value and the agent concentration. Both bismuth agent and iohexol obtained a $\mathrm{R}$ value bigger than 0.99, indicating a linear dose-response relationship. However, bismuth chelation showed a greater value of slop, indicating a stronger capacity for CT imaging than iohexol. These results indicated that the synthesized bismuth chelate possesses satisfying biocompatibility and superior capacity in CT imaging in vitro.

\section{Performance on $\mathrm{CT}$ imaging in vivo}

The bismuth agent was administrated to mice by i.v. injection for CT imaging in vivo. As shown in $2 \mathrm{D}$ and 3D CT images in Fig. 3, bismuth chelation enhanced the 

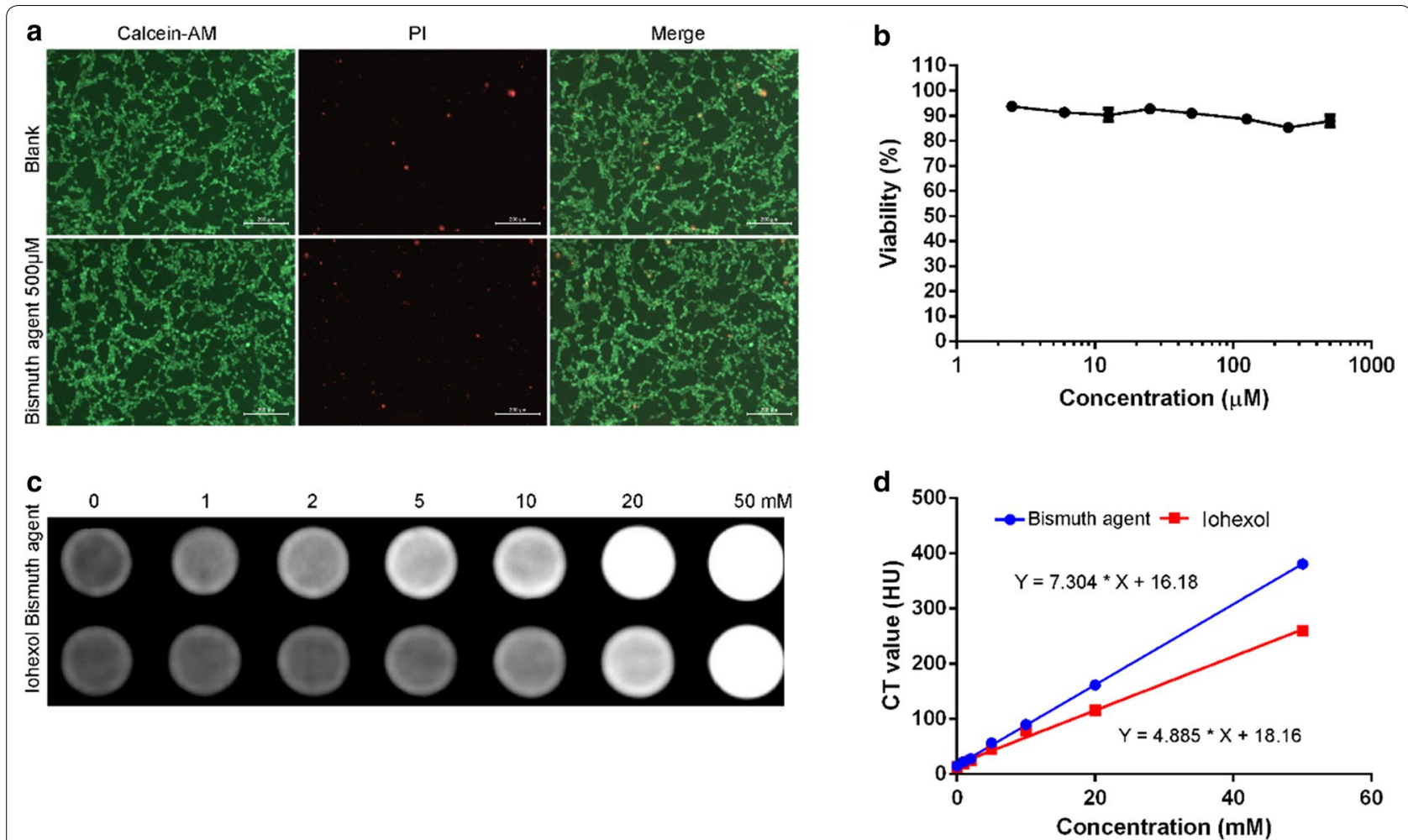

Fig. 2 a The live_-dead assay and (b) MTT test of the L02 cells treated by the bismuth agent; $\mathbf{c}$ The CT images and (d) the CT values of the bismuth agent and iohexol with different concentrations

imaging contrast of CT for kidney at 4 and 45 min after the injection, whereas iohexol provide obscured kidney image in the same experimental setting. The $\mathrm{CT}$ values of different organs were quantified in Fig. 3, compared to the iohexol, bismuth agent achieved stronger signal for kidney detection at 4, 45 and 90 min after administration. At $120 \mathrm{~min}$, the effects disappeared and the signal strength of bismuth chelation group was comparable to the blank. Iohexol induced momentary signal improvement in the kidney only in the first few minutes and, the strength decreased quickly to the base line at $45 \mathrm{~min}$. In regard of the bladder, both bismuth chelation and iohexol induced strong contrast in CT imaging, suggesting they are eliminated through urine. Despite slight enhancement, there were no significant difference between bismuth chelation and iohexol in CT imaging for other tissues including heart, liver and spleen. Above results suggested that the synthesized bismuth chelate achieved better performance for kidney CT imaging than iohexol in mouse.

\section{Pharmacokinetics, in vivo distribution and toxicity of bismuth contrast agents}

In order to measure pharmacokinetic parameters and in vivo distribution for the synthesized bismuth chelate, a standard curve was constructed for the detection of bismuth using atomic absorption spectrometry (Fig. 4a). Regression analysis revealed the coefficient of determination $\mathrm{R}^{2}=0.9971$ for linear regression. Pharmacokinetic properties were measured by administrating bismuth chelation to mice through i.v. injection. Bismuth distribution was determined in tissues including heart, liver, spleen, lung and kidney, of which kidney showed the highest concentration of bismuth (Fig. 4b). This is consistent with the results of $\mathrm{CT}$ imaging in vivo. The plasma concentration was monitored as shown in Fig. 4c and a non-linear relationship with time was observed. When the natural $\log$ of plasma concentrations were plotted with time, an approximately linear regression was obtained (Fig. 4d). These results indicated that the elimination of synthesized bismuth chelation followed the first-order elimination kinetics. Pharmacokinetic parameters were calculated by DAS and a Akaike's Information Criterion (AIC) value of - 20.927 were obtained for one-compartment model. The elimination rate constant $(\mathrm{k})$, initial concentration $\left(\mathrm{C}_{0}\right)$ and half-life time $\left(\mathrm{t}_{1 / 2}\right)$ were calculated to be $1.152 \mathrm{~h}^{-1}, 301.7 \mathrm{mg} / \mathrm{L}$ and $0.602 \mathrm{~h}$ respectively. The apparent distribution volume $(\mathrm{V})$ was calculated to be $0.617 \mathrm{~L} / \mathrm{kg}$ by dividing dosage by initial plasma concentration. The clearance $(\mathrm{CL})$ was calculated 


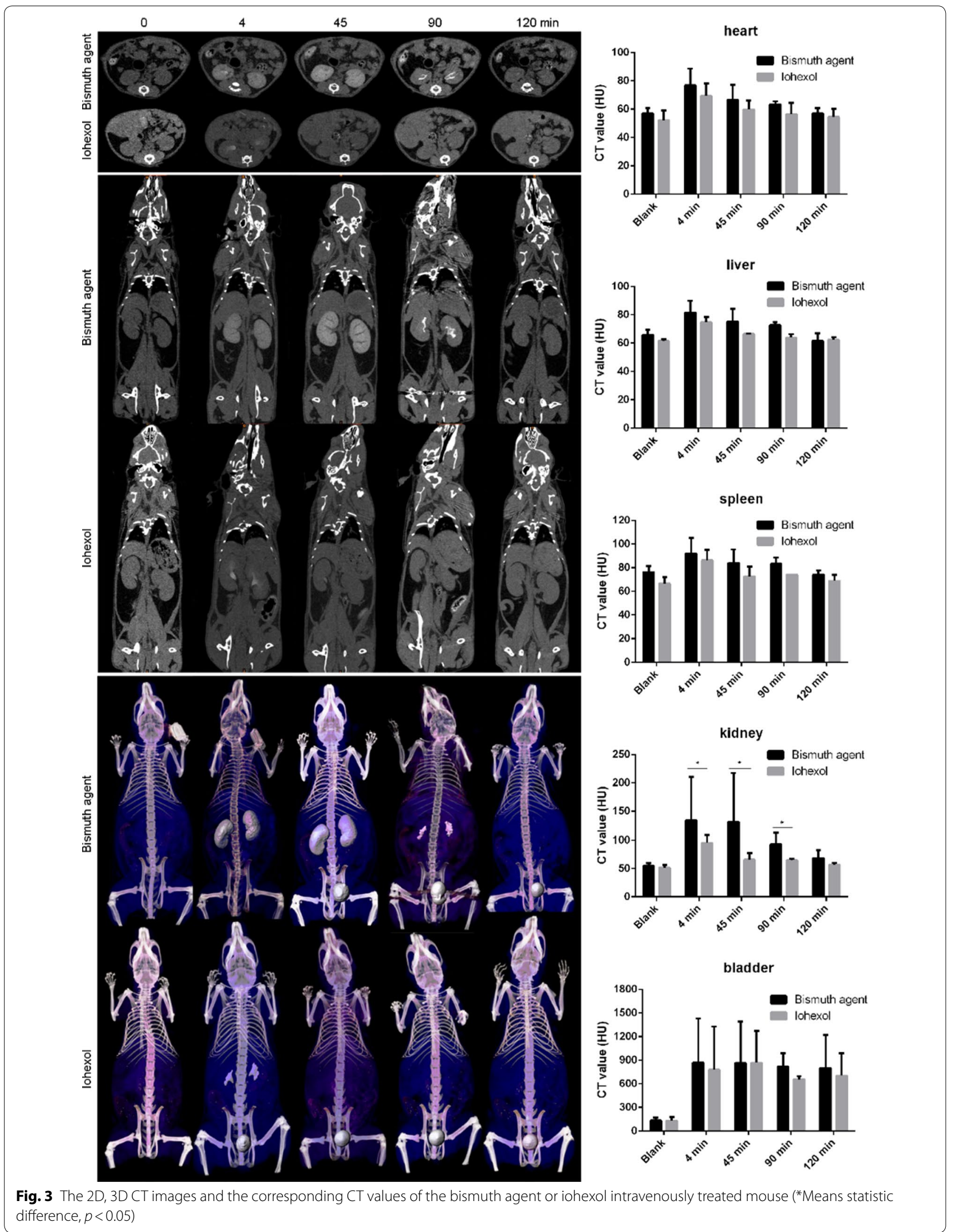



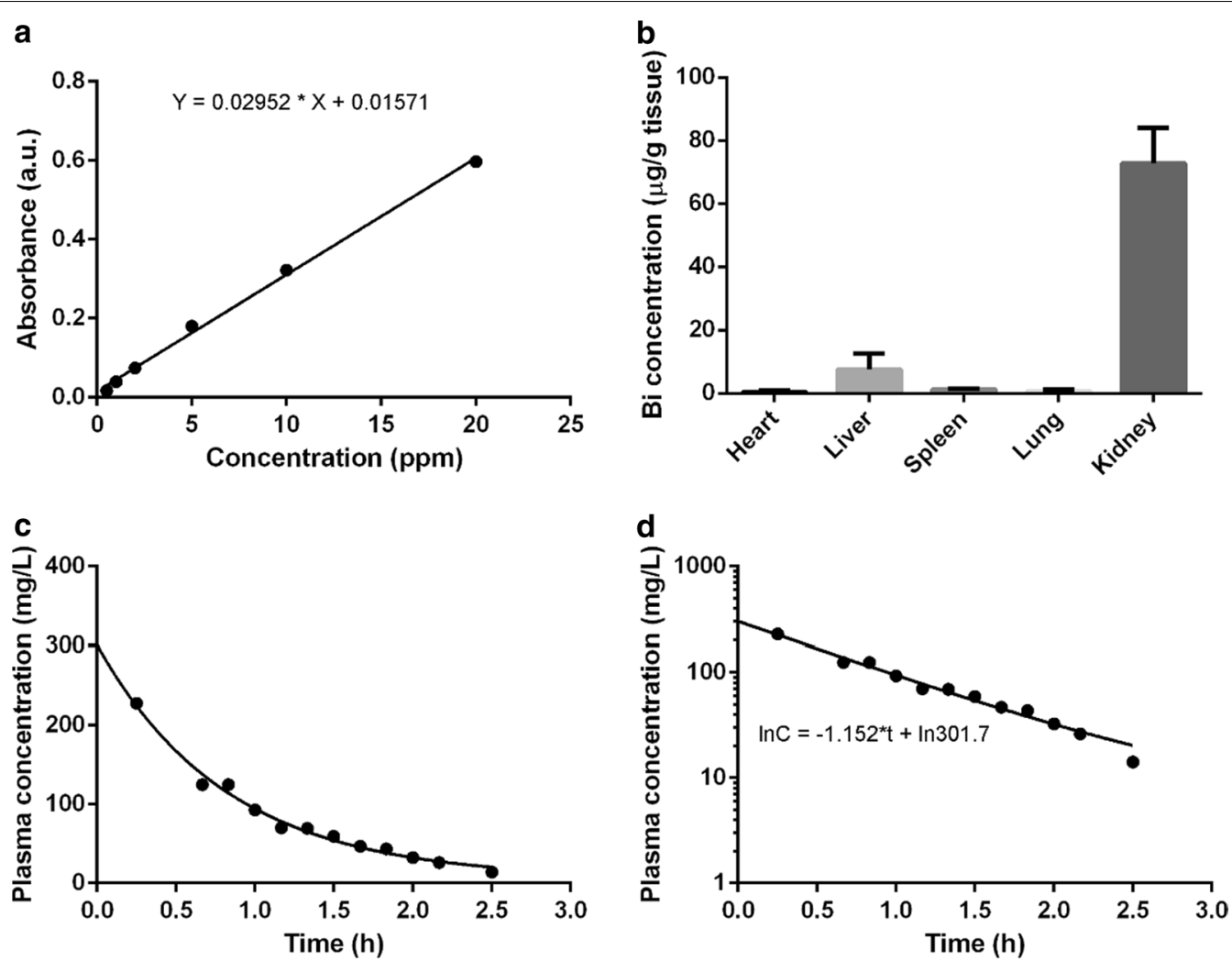

Fig. 4 a The standard curve of the Bi element measured by AAS; $\mathbf{b}$ The biodistribution of the bismuth agent in mice; $\mathbf{c}$ The blood drug concentration - time curve of the intravenously administered bismuth agent; $\mathbf{d}$ The natural log of blood drug concentrations plotted with time

to be $0.710 \mathrm{~L} /\left(\mathrm{kg}^{*} \mathrm{~h}\right)$. Area under the curve $\left(\mathrm{AUC}_{0 \rightarrow \infty}\right)$ was estimated to be $351.917 \mathrm{~h} * \mathrm{mg} / \mathrm{L}$. The short halflife time indicated that bismuth agent could be quickly excreted, which is a basic requirement for CAs from the perspective of acceptable toxicity.

The effect of bismuth agent on hemolysis was tested in a series of concentrations from 10 to $1000 \mu \mathrm{M}$ with water as a positive control and saline as a negative control. The results showed that there was no obvious hemolysis induced by bismuth chelation up to the concentration of $1000 \mu \mathrm{M}$ (Fig. 5a). Tissues were collected from mice that administrated with bismuth chelate and H\&E staining were performed (Fig. 5b). There was no apparent tissue damage in the heart, liver, kidney, lung and spleen. The results confirmed the good biocompatibility and negligible toxicity of the bismuth agent in vivo.

\section{Discussion}

In the present study, a bismuth chelate was synthesized and its potential application on X-ray computed tomography was evaluated. This bismuth agent showed no apparent toxicity in L02 cells and did not induce morphological changes of organs such as heart, liver, kidney, lung and spleen. The imaging capacity of bismuth agent is superior to iohexol as indicated by higher $\mathrm{CT}$ values in vitro as well as in vivo for the imaging of kidney. The plasma clearance of bismuth chelation followed the first-order elimination kinetics with a short half-life time of $0.602 \mathrm{~h}$, which guaranteed a short residence time in vivo and its biosafety.

Although the third generation ICAs possesses isoosmolality and induce lower incidence of side effects, they still may lead to nephropathy and adverse cardiac events [10, 13]. A clinical trial including 475 patients with myocardial infarction who undergo primary percutaneous coronary intervention compared the side effect of the second generation low-osmolar contrast medium iopromide and the third generation iso-osmolar contrast medium iodixanol on acute kidney injury and myocardial infarction [10]. The results of this study showed that both iopromide and iodixanol induced more the $10 \%$ incidence of aggravation of kidney injury and increases of the risk of myocardial infarction. Furthermore, these 2 contrast media all lead to over $5 \%$ major adverse cardiac events including cardiac death, reinfarction, and rehospitalization for heart failure within 1 month. These clinical evidence indicates that 


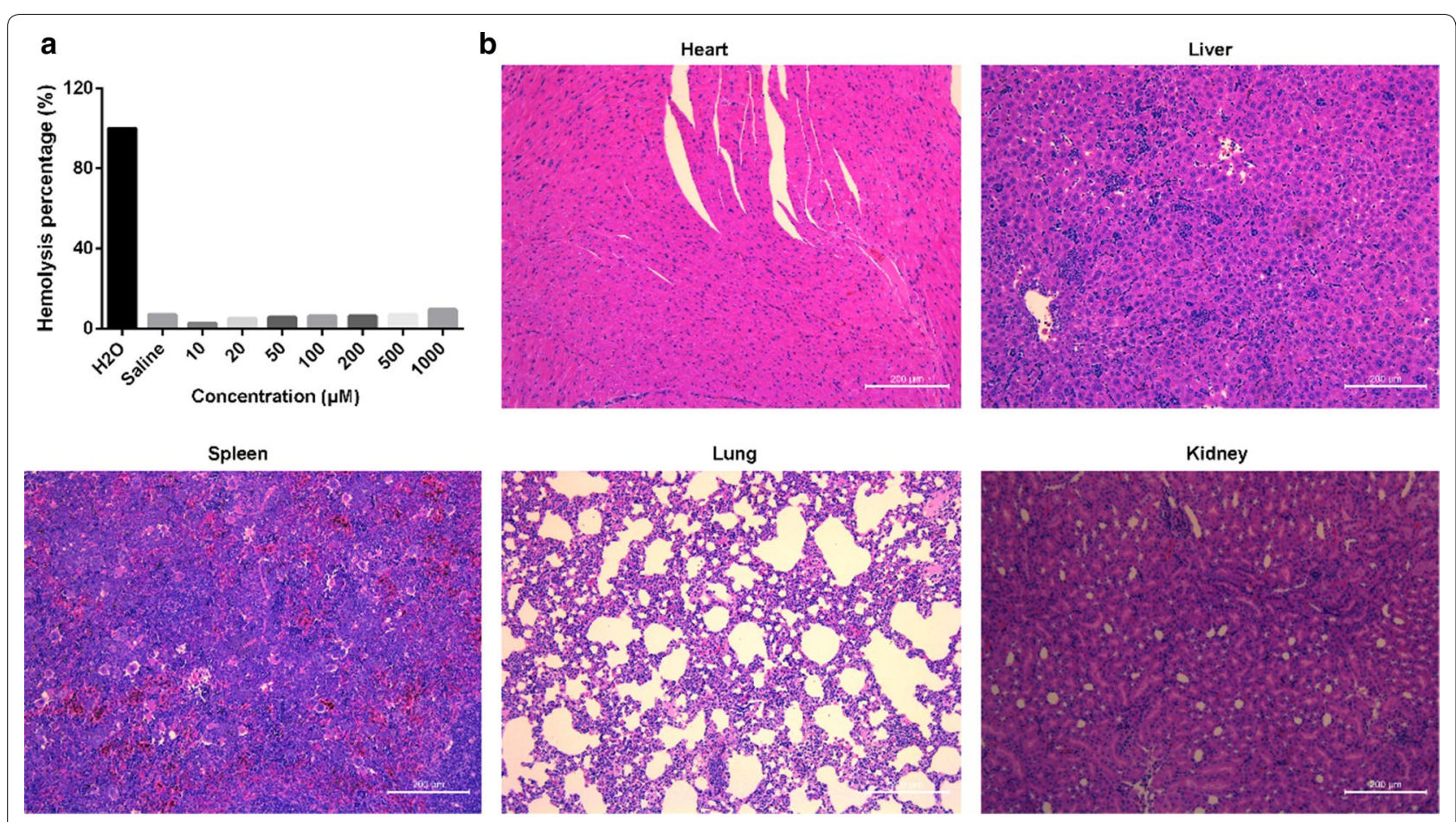

Fig. 5 a The hemolysis test of the bismuth agent; $\mathbf{b}$ The $\mathrm{H}$ \& E images of the main organs of the bismuth agent repeated treated mice

the discovery of new contrast agent with low toxicity and side effects is desperately needed.

Nanoparticles are emerging as a potential candidate for the CAs with long blood circulation time and tumortargeting capacity. Bismuth has similar imaging capacity to gold, however it is much less expensive. It has been shown that PLGA nanoparticles encapsulating bismuth nanocrystals and coumarin-6 can be used for CT and fluorescence imaging in vitro [14]. Bismuth and dodecanethiol nanoparticles were synthesized for CT imaging of gastrointestinal (GI) tract [15]. It has been suggested that bismuth nanoparticles may have synergistic effects on photothermal therapy and thermoradiotherapy. It has been shown that thiol-capped bismuth nanoparticles encapsulated by PEGylated phospholipids accumulated in tumor tissue and facilitated tumor CT imaging and thermoradiotherapy in mice [16]. Bismuth sulfide nanorods has been shown to visualized tumor and provide photothermal effects for tumor suppression in mice [17]. Although bismuth nanoparticles enhance contrast for CT imaging, their manufacture is complicated and time-consuming compared with the synthesized bismuth chelate in this study. Furthermore, the long circulation time of nanoparticles may increase the risk of side effects. However, further investigation is needed to evaluate the performance of the synthesized bismuth chelate in photothermal and radiation therapy.
The synthesized bismuth contrast agent showed low toxicity both in vitro and in vivo. Our results indicated that its imaging capacity was superior to iohexol. This allows us to adopt lower concentration of bismuth contrast agent to achieve the same strength of imaging. Lower the dose of contrast media may facilitate the reduction of toxicity. Pharmacokinetic studies indicated that the plasma clearance of this bismuth contrast agent followed first-order elimination kinetics, suggesting that the elimination rate of bismuth contrast agent is directly proportional to its plasma concentration. This reduces the risk of toxic effects that may induced by increasing the dose of drugs that followed zero-order kinetics or non-linear model. Furthermore, the limited retention time of bismuth chelate, which is indicated by a short half-life time of $0.602 \mathrm{~h}$, may also reduce the risk of side effects. Therefore, this bismuth chelate may serve as contrast agent for CT imaging.

\section{Conclusions}

In this study, bismuth agent was prepared for CT imaging by simply using DTPA as chelating agent. The preparation method is cost-effective and time-saving. The bismuth agent is superior to iohexol in the aspect of CT imaging of kidney in mice. In addition, the bismuth agent possesses low toxicity both in vivo and in vitro. Its plasma clearance followed the first-order elimination kinetics 
with a short half-life time of $0.602 \mathrm{~h}$, which means short residence time in vivo and improved biosafety. The bismuth agent was supposed to overcome the drawbacks of the clinical ICAs and bring better imaging performance. Although further clinical studies are needed, this bismuth chelate is a clinically potential candidate as CAs for CT.

\section{Supplementary information}

Supplementary information accompanies this paper at https://doi. org/10.1186/s12951-020-00669-4.

Additional file 1: Figure S1. +ESI-MS spectrum of the bismuth chelate Figure S2. The IR spectrum of bismuth agent in solution ( $\mathrm{pH} 7.0)$ after storage at $4{ }^{\circ} \mathrm{C}$ for 4 months.

\section{Abbreviations}

CT: Computed tomography; DTPA: Diethylenetriaminepentaacetic acid; CAs: Contrast agents; ICAs: lodinated contrasts agents; MRI: Magnetic resonance imaging; TEM: Transmission electron microscope; DLS: Dynamic light scatering; MTT: Methyl thiazoly tetrazolium; DMEM: Dulbecco's modified Eagle's medium; UV: Ultraviolet-visible; FTIR: Fourier transform infrared spectrum; ESIMS: Ionization mass spectrum; PI: Propidium iodide; AAS: Atomic absorption spectrum; $\mathrm{k}$ : Elimination rate constant; $C_{0}$ : Initial plasma concentration; $\mathrm{t}_{1 / 2}$ : Half-life time; V: Apparent distribution volume; CL: Clearance; $\mathrm{AUC}_{0 \rightarrow \infty}$ : Area under the curve; RBCs: Red blood cells.

\section{Acknowledgements}

The authors thanks Min-yan Wei, Xin Li, Ling-ran Du, Guo-dong Ye, Guangquan Mo, Yu-juan Guo and Chu-wen Li for their useful suggestions.

\section{Authors' contributions}

$J F, S L$ and $L Z$ proposed this idea and supported the project, JF, JG and AQ carried out most of the experiments, $X Y, Q Z, X L, Y H, M C, J L, Y Z, J L, Y D, D W$, $X Z, Y L$ and $Z L$ helped in this project. All authors read and approved the final manuscript.

\section{Funding}

This work was supported by the National Natural Science Foundation of China (No. 81803463, 81903607, 81870142, 51403043, 51803028) and, the Natural Science Foundation of Guangdong Province (No. 2018A030310183, 2015A030310428) and, Science and Technology Program of Guangzhou (No. 907181975046) and Traditional Chinese Medicine Program of Guangdong Province (No. 20201208), the scientific research start-up fund for high-level talents of Foshan University (gg07077) and the Foshan Functional Polymer Engineering Center (2016GA10162)..

\section{Availability of data and materials}

All data used to generate these results is available in the main text.

\section{Ethics approval and consent to participate}

The study was approved by Ethics Committee of Guangzhou Medical University.

\section{Consent for publication}

Not applicable.

\section{Competing interests}

The authors declare that they have no competing interests.

\section{Author details}

${ }^{1}$ The Fifth Affiliated Hospital of Guangzhou Medical University, Guangzhou Medical University, Guangzhou 510700, Guangdong, China. ${ }^{2}$ Department of Medical Imaging, The Third Affiliated Hospital, Southern Medical University, Guangzhou, China. ${ }^{3}$ The Third School of Clinical Medicine, Southern Medical University, Guangzhou, China. ${ }^{4}$ School of Materials Science and Energy Engineering, Foshan University, Foshan 528000, China. ${ }^{5}$ Department of Medical
Imaging, Guangzhou First People's Hospital, School of Medicine, South China University of Technology, Guangzhou, China.

Received: 4 March 2020 Accepted: 30 July 2020

Published online: 06 August 2020

\section{References}

1. Prodi L, Rampazzo E, Rastrelli F, Speghini A, Zaccheroni N. Imaging agents based on lanthanide doped nanoparticles. Chem Soc Rev. 2015;44:4922-52.

2. Dou Y, Guo Y, Li X, Li X, Wang S, Wang L, Lv G, Zhang X, Wang H, Gong $X$, Chang J. Size-tuning ionization to optimize gold nanoparticles for simultaneous enhanced CT imaging and radiotherapy. ACS Nano. 2016;10:2536-48

3. Bottinor W, Polkampally P, Jovin I. Adverse reactions to iodinated contrast media. Int J Angiol. 2013;22:149-54.

4. Motosugi U, Ichikawa T, Sano K, Onishi H. Acute adverse reactions to nonionic iodinated contrast media for $\mathrm{CT}$ : prospective randomized evaluation of the effects of dehydration, oral rehydration, and patient risk factors. AJR Am J Roentgenol. 2016;207:931-8.

5. LOCAT Group. Low-dose CT for the diagnosis of appendicitis in adolescents and young adults (LOCAT): a pragmatic, multicentre, randomised controlled non-inferiority trial. Lancet Gastroenterol Hepatol. 2017;2:793-804.

6. Lubbers MM, Kock M, Niezen A, Galema T, Kofflard M, Bruning T, Kooij HS, van Valen H, Dijkshoorn M, Booij R, Padmos A, Vogels A, Budde RPJ, Nieman K. lodixanol versus lopromide at coronary CT angiography: lumen opacification and effect on heart rhythm-the randomized IsoCOR trial. Radiology. 2018;286:71-80.

7. Terrenato I, Sperati F, Musicco F, Pozzi AF, di Turi A, Caterino M, de Lutio di Castelguidone E, Setola SV, Bellomi M, Neumaier CE, Conti L, Cigliana G, Merola R, Antenucci A, Orlandi G, Giordano A, Barba M, Canitano S. Iodixanol versus iopromide in cancer patients: evidence from a randomized clinical trial. J Cell Physiol. 2018;233:2572-80.

8. Song T, Song M, Ge Z, Li Y, Shi P, Sun M. Comparison of the nephrotoxic effects of iodixanol versus iohexol in patients with chronic heart failure undergoing coronary angiography or angioplasty. J Interv Cardiol. 2017:30:281-5.

9. Heinrich MC, Kuhlmann MK, Grgic A, Heckmann M, Kramann B, Uder M. Cytotoxic effects of ionic high-osmolar, nonionic monomeric, and nonionic iso-osmolar dimeric iodinated contrast media on renal tubular cells in vitro. Radiology. 2005;235:843-9.

10. Bolognese L, Falsini G, Schwenke C, Grotti S, Limbruno U, Liistro F, Carrera A, Angioli P, Picchi A, Ducci K, Pierli C. Impact of iso-osmolar versus lowosmolar contrast agents on contrast-induced nephropathy and tissue reperfusion in unselected patients with ST-segment elevation myocardial infarction undergoing primary percutaneous coronary intervention (from the Contrast Media and Nephrotoxicity Following Primary Angioplasty for Acute Myocardial Infarction [CONTRAST-AMI] Trial). The American journal of cardiology. 2012;109:67-74.

11. Ford AC, Malfertheiner P, Giguere M, Santana J, Khan M, Moayyedi P. Adverse events with bismuth salts for Helicobacter pylori eradication: systematic review and meta-analysis. World J Gastroenterol. 2008;14:7361-70

12. Cormode DP, Naha PC, Fayad ZA. Nanoparticle contrast agents for computed tomography: a focus on micelles. Contrast Media Mol Imaging. 2014:9:37-52

13. Azzalini L, Vilca LM, Lombardo F, Poletti E, Laricchia A, Beneduce A, Maccagni D, Demir OM, Slavich M, Giannini F, Carlino M, Margonato A, Cappelletti A, Colombo A. Incidence of contrast-induced acute kidney injury in a large cohort of all-comers undergoing percutaneous coronary intervention: Comparison of five contrast media. Int J Cardiol. 2018;273:69-73.

14. Swy ER, Schwartz-Duval AS, Shuboni DD, Latourette MT, Mallet CL, Parys M, Cormode DP, Shapiro EM. Dual-modality, fluorescent, PLGA encapsulated bismuth nanoparticles for molecular and cellular fluorescence imaging and computed tomography. Nanoscale. 2014;6:13104-12.

15. Wei B, Zhang X, Zhang C, Jiang Y, Fu YY, Yu C, Sun SK, Yan XP. Facile synthesis of uniform-sized bismuth nanoparticles for CT visualization of gastrointestinal tract in vivo. ACS Appl Mater Interfaces. 2016;8:12720-6. 
16. Yu N, Wang Z, Zhang J, Liu Z, Zhu B, Yu J, Zhu M, Peng C, Chen Z. Thiol-capped Bi nanoparticles as stable and all-in-one type theranostic nanoagents for tumor imaging and thermoradiotherapy. Biomaterials. 2018;161:279-91.

17. Liu J, Zheng X, Yan L, Zhou L, Tian G, Yin W, Wang L, Liu Y, Hu Z, Gu Z, Chen $C$, Zhao $Y$. Bismuth sulfide nanorods as a precision nanomedicine for in vivo multimodal imaging-guided photothermal therapy of tumor ACS Nano. 2015;9:696-707.

\section{Publisher's Note}

Springer Nature remains neutral with regard to jurisdictional claims in published maps and institutional affiliations.
Ready to submit your research? Choose BMC and benefit from:

- fast, convenient online submission

- thorough peer review by experienced researchers in your field

- rapid publication on acceptance

- support for research data, including large and complex data types

- gold Open Access which fosters wider collaboration and increased citations

- maximum visibility for your research: over $100 \mathrm{M}$ website views per year

At BMC, research is always in progress.

Learn more biomedcentral.com/submissions 